\title{
USING NATURAL LANGUAGE PROCESSING TO DETECT URBAN PROBLEMS FOR GOVERNANCE
}

\author{
Jing $\mathrm{Li}^{1}$, Chunhua Cao ${ }^{1}$, Yue Luo ${ }^{1}$, Xiaobo $\mathrm{He}^{1}$, Xian Liu ${ }^{1}$, Yahui Jia ${ }^{1}$, Xianfeng Jin ${ }^{1}$, Shu Wang ${ }^{1}$, \\ Jiying Run ${ }^{1}$, Xin Su${ }^{1}$, Yuxuan Zhong ${ }^{1}$, Qiuhan Zhao ${ }^{2}$, Zifu Wang ${ }^{2}$ and Megan Rice ${ }^{2}$ \\ ${ }^{1}$ Chongqing Geomatics and Remote Sensing Center, 339 Longshan Road, Yubei District, Chongqing, China \\ ${ }^{2}$ NSF Spatiotemporal Innovation Center, George Mason University, Fairfax, VA 22031, USA
}

\begin{abstract}
Urban informatics has become an increasingly important domain in the past few years. At the same time, the volume and variety of urban data resources has become increasingly diversified and larger. These sources include the millions of emails that serve as an invaluable communication mechanism between citizens and municipal managers. The responses to these emails could benefit from urban analyses, such as through location and tracking. By analyzing key information such as the subject content and spatial location, we can discover whether any major problems in a certain city or any long-term problems have been resolved. However, processing such large number of emails manually is tedious - for example, a secretary can only process approximately 100 emails per day. This paper uses deep learning, machine learning, and natural language processing to mine and analyze government-related emails in a semi-automated process. In this method, the email content is first cut and digitized by natural language processing technology. Then, the digitized text content is modeled by different algorithms through machine learning and deep learning technology — the accuracy of each algorithm is compared with one another. Finally, the emails can be automatically classified into a variety of topics, automatically analyzing the problems in the city. This proposed process greatly improves the efficiency of analyzing city information which could ultimately help governments optimize their resources and support their decision making.
\end{abstract}

\section{KEYWORDS}

Urban Informatics, Deep Learning, Machine Learning, Big Data

\section{INTRODUCTION}

With the rapid development of technology, the volume of urban information has dramatically increased. Correspondingly, the channels for obtaining such information have also increased. With these advancements, information that has typically been collected manually can now be collected more efficiently through Internet resources. Indeed, utilizing internet-based data is becoming a more common method for collecting urban-related data (Thakuriah et al., 2017). These data sources include the millions of emails sent to municipal managers containing complaints, comments, and suggestions (Coussement and Van den Poel, 2008; Halaris et al., 2007). The mayor's email box can be used to easily collect important information regarding city issues. The government will directly reply to these letters and assign certain departments to address the relevant content in each email.

The government is also responsible for managing all the key information included in these emails such as the title, publishing unit, release time, link, ID, content, reply, and handling unit. This information plays an important role in urban analysis. In fact, we can use this data to discover whether the major problems in a certain city or any problems over time have been resolved. However, from October 10, 2013 to June 6, 2020, citizens sent a total of 410,000 emails. Manual inspection and analysis of this large email volume is not very efficient - a secretary can only process approximately 100 emails per day.

This paper uses natural language processing technology to mine and analyze citizens' emails. The content of these emails is first cut and digitized by natural language processing technology. Then, this digitized text is modeled by machine learning and deep learning technology. With these models, the emails in the city government email box can be automatically classified according to a variety of topics. Ultimately, this process works to improve the efficiency of analyzing city information by automatically classifying problems which has benefits and applications in a city's decision-making and problem-solving. 


\section{SYSTEM DESIGN}

\subsection{System Architecture}

The entire system in this study uses a deep learning approach to model and efficiently analyze the subject classification of 410,000 emails. The model building process is divided into the following seven steps. 1) Manually tagging all data with corresponding tags to serve as the raw data that the model needs to learn. 2) Finding the appropriate Chinese word vector embedding file for vectorizing the word (word 2 vec), each word has its own dimension attribute. 3) Preprocessing the data, such as with the segmentation of sentences and the removal of stopwords and punctuation 4) Training and optimizing the model according to the corresponding word dimensions in the Chinese word vector embedding file 5) Using a testing data set to evaluate the model. 6) Using active learning to optimize the model. 7) Inputing 410,000 emails into the model and categorizing them by using Spark parallel computing to improve computing efficiency. The following figure (Figure 1) shows the architecture of the system.

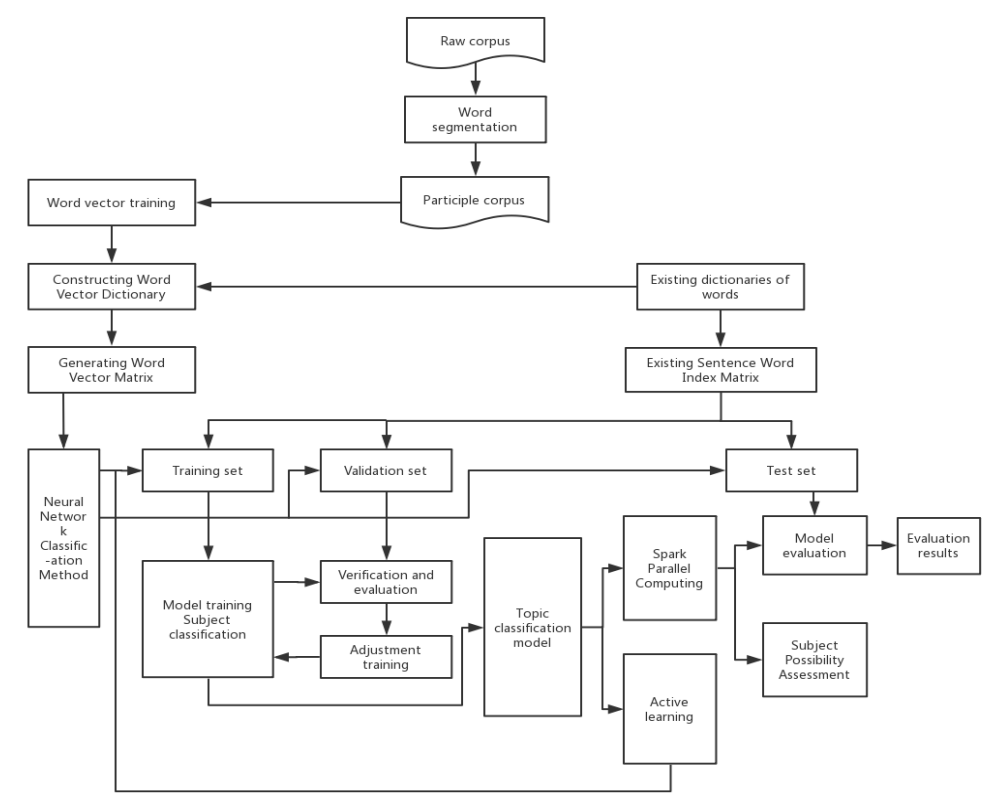

Figure 1. The architecture of the system

\subsection{Data Description}

The data used in this system represents emails from October 10, 2013 to June 6, 2020. The data collection takes place from various district and county governments in Chongqing - including the Municipal Finance Bureau, the Urban Management Committee, the Urban and Rural Construction Committee, the Archives Bureau, the Electric Power Company, the Local Taxation Bureau, and the Industrial and Commercial Bureau, Development and Reform Commission, Poverty Alleviation Office, Public Security Bureau, Planning Bureau, State Taxation Bureau, Land and Housing Authority, State-owned Assets Supervision and Administration Commission, Environmental Protection Bureau, Communications Commission, Education Commission, Quality Supervision Bureau, Price Bureau, Health Bureau, Health and Family Planning Commission, Communications Administration, the Judicial Bureau, the Sports Bureau, the Water Resources Bureau, the Tourism Bureau, the Civil Affairs Bureau, the Human Resources and Social Security Bureau, the Commercial Committee, the Food and Drug Administration, and the Political Commissar. This data covers topics such as real estate, economics, public affairs, governmental affairs, the urban environment, 
transportation, food, and crimes. By processing these data, designing experiments, and building models, the machine can automatically classify the topics of 410,000 emails based on the email content. This classification will help efficiently reveal the main problems in Chongqing.

In deep learning, the machine needs the original data to be tagged before it is able to learn. To do this, 5,204 public e-mails were randomly selected from the 410,000 in total. Emails in this subset were divided based on 10 primary classification categories and 22 secondary classification categories. This annotation process was divided among several labelers, however, there was strong inter-rater agreement. The breakdown of each class is shown in the table below (Table 1). The subsequent natural language processing steps were carried out on all emails regardless of category.

Table 2. Two different classifications of emails and their numbers of sample emails

\begin{tabular}{|c|c|c|c|}
\hline Primary classification & Number & Secondary classification & Number \\
\hline Government real estate -0 & 232 & Real estate dispute -0 & 232 \\
\hline Economic dispute -1 & 273 & Economic dispute -1 & 273 \\
\hline Utility service - 2 & 231 & $\begin{array}{l}\text { Utility facilities }-2 \\
\text { Facility proximity avoidance }-3\end{array}$ & $\begin{array}{l}129 \\
102\end{array}$ \\
\hline Public service -3 & 552 & $\begin{array}{l}\text { Education related }-4 \\
\text { Medical related }-5 \\
\text { Living service facilities }-6\end{array}$ & $\begin{array}{l}264 \\
169 \\
119\end{array}$ \\
\hline Government service -4 & 1475 & $\begin{array}{l}\text { City planning consultation }-7 \\
\text { Government affair }-8\end{array}$ & $\begin{array}{l}219 \\
1256 \\
\end{array}$ \\
\hline Urban environment -5 & 1271 & $\begin{array}{l}\text { Urban hidden hazards - } 9 \\
\text { Pedestrian management }-10 \\
\text { Construction effects - } 11 \\
\text { Environment pollutions - } 12 \\
\text { Comprehensive environment order - } 13\end{array}$ & $\begin{array}{l}143 \\
230 \\
375 \\
417 \\
104\end{array}$ \\
\hline Road traffic -6 & 757 & $\begin{array}{l}\text { Illegal parking }-14 \\
\text { Traffic control - } 15 \\
\text { Transportation implementation }-16 \\
\text { Public transportation }-17 \\
\text { Comprehensive traffic order }-18 \\
\end{array}$ & $\begin{array}{l}125 \\
184 \\
130 \\
218 \\
100\end{array}$ \\
\hline Estate commercial management -7 & 150 & Estate commercial management - 19 & 150 \\
\hline $\begin{array}{l}\text { Food safety }-8 \\
\text { Illegal crime }-9\end{array}$ & $\begin{array}{l}165 \\
98\end{array}$ & $\begin{array}{l}\text { Food safety }-20 \\
\text { Illegal crime }-21\end{array}$ & $\begin{array}{l}165 \\
98\end{array}$ \\
\hline
\end{tabular}

\section{EXPERIMENT PROCEDURE}

\subsection{Data Preprocessing}

\subsubsection{Word Segmentation}

The content in this email set was complicated; if the entire text content is directly learned by computers, the model and forecasting theme would have a large error. Therefore, before the learning process, it is necessary to preprocess the email data. This step included splitting the content of each message into several phrases. This study used "Jieba Chinese text segmentation" to disassemble the emails (Sun, 2012). The Jieba Chinese text segmentation tool used a Trie tree to scan the text paragraphs. This resulted in a Directed Acyclic Graph (DAG) which contained all possible word combinations of Chinese characters. The words could then be identified through the frequency, weight, attributes, and other word library rules. The words and phrases that were separated as text preprocessed data were then used for modeling and testing (Sun, 2012).

To provide a further explanation, we use “观音桥需要修建垃圾场 (The Guanyin Bridge needs to build landfill)" as an example. Each character in this sentence represents a node, and a DAG is generated according to the words that can be combined at each point (Figure 2). 


\section{“沁音格需要修建垃圾场”}

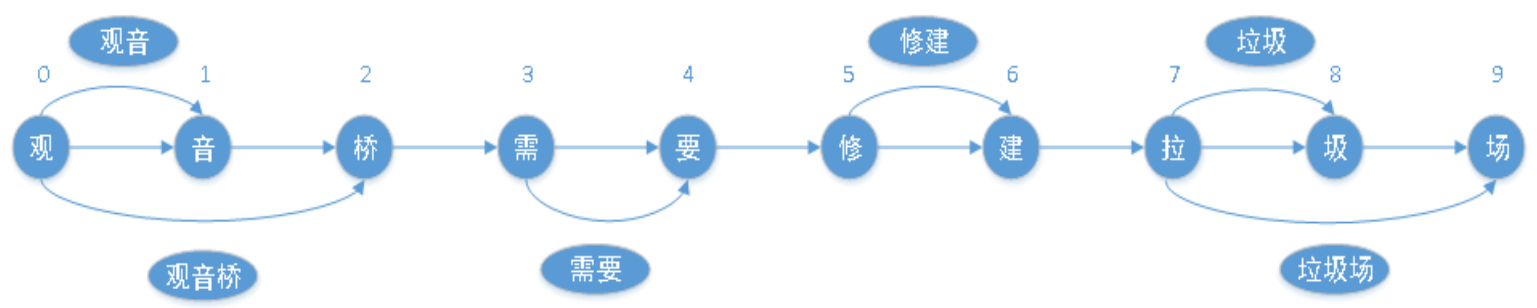

Figure 2. "Jieba Chinese text segmentation" running process

After obtaining the phase-free graph, the DP dynamic rule is used to solve the maximum probability path. Each node in this path has a weight ratio W. We can also get multiple paths where each route has a different combination of nodes.

$$
\text { route }=\left(w_{1}, w_{2}, w_{3}, \ldots, w_{n}\right)
$$

The optimal path maximizes $\operatorname{\sum weight}\left(w_{i}\right)$, which is the sum of all node weights to complete the word segmentation. In this way, "观音桥需要修建垃圾场" will be split into "观音桥 (Guanyin Bridge), 需要 (needs to), 修建(build), 垃圾场(landfill)".

\subsubsection{Removal of Stopwords and Punctuation}

After completing the word segmentation, a stopword lexicon is needed to filter the noise. These emails include common modal particles such as "right", "you", "me", and "thanks", as well as other nouns and verbs that are collectively referred to as noise. It is important to remove noise through a stopword lexicon filter so that it does not impact the accuracy of the model. All numbers and punctuation are filtered directly in the code (Ferilli et al., 2014).

\subsection{Feature Engineering}

In feature engineering, raw data is converted to feature vectors, and new features are created based on existing data. To select important features from the data set, we conducted experiments by use the following preprocessed email as an example. This email mainly describes the water leaking of the house and the poor attitude of property management department. There are 296 words in this sample email.

['您好', '万科', '锦程', '栋', '业主', '入住', '半个', '楼下', '天花板', '渗水', '我家', '生活', '阳台', '墙面', '略有', ' 起泡', '经物管', '检测', '发现', '我家', '生活', '阳台', '漏水', '㨹开', '生活', '阳台', '地下水', '破裂', '交房', '安 装', '水管', '残次品', '且验', '房时', '经物', '管测', '水压', '显示', '怀疑', 验收', '阶段', '蓄意', '欺骗', '业主', '楼 下', '我家', '生活', '阳台', '墙面', '再次出现', '找物', '管及', '万科', '维修', '对接', '人员', '更换', '离职', '交接', ' 失职', '电话', '报修', '未', '做', '记录', '或物管', '蓄意', '近期', 物管', '维修部', '撤场', '态度', '蛮横', '恶劣', '交 接', '失职', '过往', '保修', '记录', '矢口否认', '隐蔽', '工程', '上次', '修缮', '责任', '推卸', '业主', '我家', '卫生 间', '防水', '墙面', '渗水', '楼层', '诸如此类', '精装', '房', '质量', '万科', '楼下', '临街', '商铺', '出租', '销售', '作 ', '火锅', 餐饮', '烟道', '密闭性', '差', '住', '楼', '晚上', '仍能', '闻到', '油烟味', '市长', '信箱', '记录', '查询', '类 似', '投诉', '充分说明', '历经', '多年', '万科', '未', '解决', '妥善解决', '主管部门', '请', '修建', '楼盘', '相关', ' 警示', '督促', '应尽', '修缮', '义务', '知名', '开发商', '应', '阻碍', '业主', '成立', '业主', '委员会', '应有', '权利', ' 请', '调查', '来信', 您好', '感谢您', '重庆', '城乡建设', '工作', '关心', '支持', '来信', '万科', 锦程', '栋', '精装', ' 房', '房屋', '质量', '相关', '现', '回复', '生活', '阳台', '水管', '漏水', '楼下', '物管', '接到', '报修', '检查', '地漏', ' 管道', '破损', '导致', '漏水', '栋', '竣过', '验收', '房屋建筑', '工程质量', '保修', '办法', '业主', '建设', '单位', ' 签定', '工程质量', '保修', '书', '约定', '工程', '电气系统', '排水管道', '设备', '安装', '保修期限', '工程', '竣工', 
'验收', '合格', '之日起', '质量', '超过', '质量', '保修期', 物管', '维修', '收取', '费用', '渝中区', '建交', '委', '收 到', '来信', '得知', '支付', '费用', '物业', '工作人员', '维修', '解决', 烟道', '密封性', '较差', '楼下', '餐馆', '营 业', '油烟', '烟道', '缝隙', '渗透', '油烟味', '居民', '生活', '影响', '工程', '采用', 烟道', '砖', '砌', '烟道', '抹', '水 泥砂浆', '表面', '封闭', '水泥砂浆', '局部', '开裂', 致使', '油烟', '从隙', '渗透', 装修', '工程质量', '保修期', ' 超过', '质量', '保修期限', '涉及', '公共', '区域', '质量', '建议', '向物', '管及', '房管局', '动用', '大修', '基金', ' 整改', '邮件', '承办', '单位', '重庆市', '渝中区', '建交', '委', '万科', '锦程', '栋', '精装', '房', '质量', '维修', '依然 ', '漏水', '万科', '拖延']

\subsubsection{TF-IDF Vector as Feature}

The TF-IDF score represented the relative importance of words in each email and the entire corpus. The TF-IDF score consisted of two parts: the standard word frequency (TF), and the inverse email frequency (IDF). The total number of emails in the corpus is divided by the number of emails containing the word, and the logarithm is represented by the inverse email frequency (Lilleberg et al., 2015).

The main idea of TF-IDF is that if a word or phrase appears in an article with a high frequency TF and is rarely found in other articles, the word or phrase is considered to have a good class distinguishing ability and is suitable to use for classification. The higher the TF-IDF value for a word or phrase, the stronger its predictive subject ability. If the TF-IDF value for a word or phrase is 0 , then it should be deleted (Lilleberg et al., 2015).

- $T F(t)=($ The number of times the word appeared in the email $) /($ The total number of words in the email)

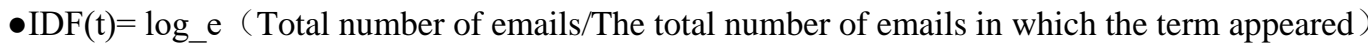

The word-level in TF-IDF was a matrix which represented the TF-IDF score for each word in a different email. For example, if the sample email was converted to the word-level in TF-IDF, the word “漏水” (leakage) is converted to " 5478 ".

$[3776,122,0,0,339,1203,1834,5030,2795,5432,3853,5726,7824,2615,0,0,0,5020,2046,3853$, $5726,7824,5478,0,5726,7824,0,6011,709,2945,5194,0,0,3899,0,0,5182,4661,3715,8073,7826,0$, 5067, 339, 5030, 3853, 5726, 7824, 2615, 1387, 0, 0, 122, 6482, 3093, 792, 4703, 6069, 711, 2811, 5806, 4052, 0, 0, 6945, 0, 0, 7430, 5590, 0, 4305, 3717, 6776, 3759, 711, 2811, 7396, 1038, 6945, 0, 7886, 3273, $183,1089,7119,4234,339,3853,1937,7814,2615,5432,5033,0,0,0,7139,122,5030,511,2335,1486$, 7742, 0, 5493, 8036, 5527, 0, 0, 0, 0, 4666, 0, 7806, 5266, 3355, 1075, 6945, 4941, 6324, 4032, 0, 0, 2694, $122,0,6901,2861,549,0,1083,5039,5919,6918,5964,0,1089,564,5971,3560,0,7830,339,3838,339$, 2870, 3470, 4860, 0, 7074, 4889, 3776, 3817, 7677, 2559, 3246, 1334, 4318, 4889, 122, 0, 0, 0, 0, 3893, 7139, 5919, 0, 2386, 5726, 7824, 5194, 5478, 5030, 5590, 4207, 4052, 5018, 0, 6320, 6008, 3104, 5478, 0, 0, 8073, 3897, 3280, 1038, 1665, 339, 3539, 1869, 6274, 3280, 1038, 0, 6379, 3273, 0, 0, 6960, 2945, 0, 3273, $6173,8073,2169,578,7139,7219,7139,1039,5590,6482,4328,7164,5434,3513,0,4327,4889,3683$, $4315,7164,5577,3247,6482,6901,5527,0,7355,5030,8038,6747,5265,5527,6509,0,5266,3195$, $5726,3657,3273,7665,5527,0,0,5527,0,0,6839,3108,0,3182,3583,6688,5265,0,0,6846,3280$, 1039, 7219, 7139, 0, 5377, 1254, 1771, 7139, 3537, 0, 0, 3905, 1709, 2719, 2592, 4434, 7621, 4006, 1869, $7680,5434,3513,0,122,0,0,0,0,7139,6482,1027,5478,122,4105]$

\subsubsection{Word Embedding (Chinese Word Vector) as Feature}

The word embedding process used dense vectors to represent words and documents. The position of a word in a vector space was learned from the context of the email. Word embedding can be trained using the input corpus itself or it can be generated using a pre-trained word embedding model. The Chinese word vector expressed each word as a digital matrix so that each sentence in a message could be quantified numerically. Statistics were calculated by analyzing characteristics such as the word frequency; then subject classification keywords were found (Tang et al., 2014). The Chinese word vector made it possible to analyze natural language in numerical terms which was convenient for use in subsequent mathematical formulas.

Different Chinese word embedding files have different sizes, which means the amount of words in each Chinese word vector is also different. If you search for “漏水(leakage)" in Weibo embedding files, there will be “漏水(leakage)” and “不漏水 (no leakage)”. However, in the People's Daily Newspaper embedding files, the same search for “漏水(leakage)” will result in “漏水(leakage)”, “不漏水(no leakage)”, and “漏水口 
(leaking gap)". Moreover, different Chinese word vector files have different word vectors, which means that the same word has a matrix of the size $1 * 300$ with different values in different embedding files.

In order to better show the difference between the four different Chinese word vectors, we compared the three-dimension place of keywords in each sample email: “漏水(leakage), 渗水(seepage), 检测(detection), 地下(underground), 水管(water pipe), 维修(maintenance), 破裂(rupture)”. Through utilizing a specific Chinese embedding coordinate system, it was found that the closer two words were, the more similar the semantics were. Overall, the aggregation of these keywords in the Mix-Large embedding file and Weibo embedding file was very high while the aggregation of these keywords in Zhihu embedding was the lowest.
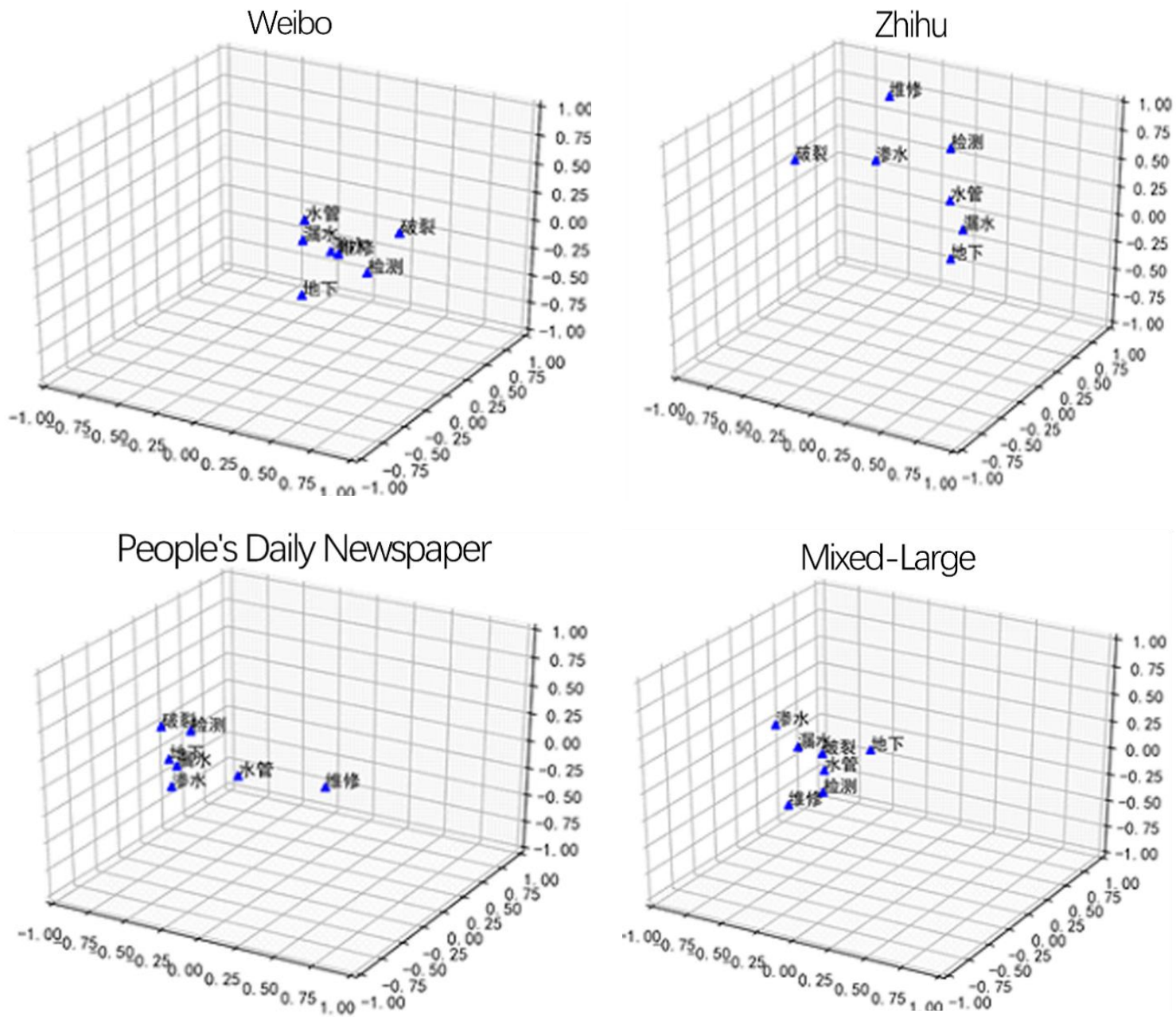

Figure 3. Vector of keywords from the sample email in Weibo, People's Daily Newspaper, Zhihu, and Mixed-Large Chinese word vectors file

Figure 3 emphasizes the concept of qualitative semantic relations. Quantitative analysis provided further information on different Chinese word vectors. In the following table, we compared the similarity of keywords in each Chinese word vector file and calculated the similarity between the two groups of keywords. The higher the similarity value of two groups of words (in this Chinese word vector space), the closer the semantics were. We expected that there would be a high similarity between water leakage and seepage and, therefore, a good semantic similarity. On the other hand, we expected that the higher the repair and rupture similarity value, the better, as this would mean that the context is highly expressive. Figure 4 compares the similarity of seven keywords in different Chinese word vector spaces. The similarity between leakage and seepage is the highest in People's Daily and Comprehensive, while the similarity between maintenance and rupture is the highest in the synthesis. In general, the comprehensive Chinese word vector is more expressive of semantics and context than the other three groups of Chinese word vectors. 


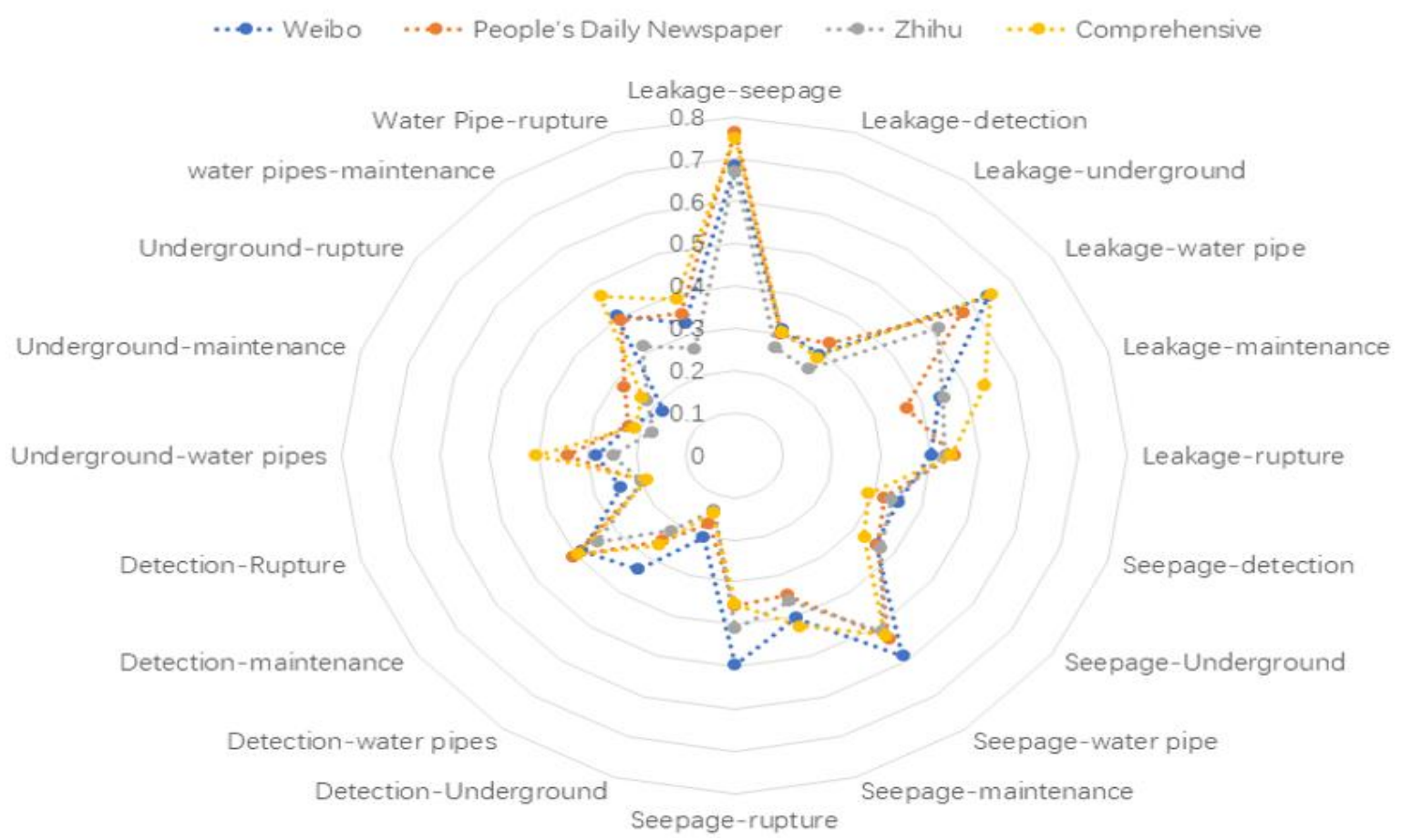

Figure 4. Comparison of similarity between keywords from the sample in different Chinese word vector spaces

\subsection{Model Selection}

\subsubsection{Machine Learning Experimental Results Comparison}

In the first set of comparative experiments, we directly used the first-level classification test to compare the training accuracy and test accuracy of three traditional machine learning algorithms. These were Support Vector Machine (Wang et al., 2006), Logistic Regression (Xu et al., 2012), and Random Forest (Genkin et al., 2007). These algorithms used TF-IDF as the Feature to train their respective models. The results showed that the SVM had the highest test accuracy (0.8442) while the RF test accuracy was the lowest. $(0.7750)$. In the second set of comparative experiments, we directly used the second-level classification test to compare the training accuracy and test accuracy of these three traditional machine learning methods. The results showed that the SVM had the highest test accuracy (0.7788) while the RF test accuracy was again the lowest (0.6913).

The test accuracy of the second group of experiments (secondary classification: 22 categories) was significantly lower than that of the first group of experiments (primary classification: 10 categories). While the number of different categories increased, the training data in each category decreased. Therefore, there was no way for the model to learn more details and deep features-which ultimately reduced the test accuracy.

Table 2. Comparison of accuracy of traditional machine learning models (using TF-IDF as Feature)

\begin{tabular}{l|l|l|l|l}
\hline & \multicolumn{3}{|l|}{ Primary classification (10 categories) } & \multicolumn{2}{l}{ Secondary classification (22 categories) } \\
\hline Algorithm & Training Accuracy & Testing Accuracy & Training Accuracy & Testing Accuracy \\
\hline Support Vector Machine & 0.9570 & 0.8442 & 0.9500 & 0.7788 \\
Logistic Regression & 0.9025 & 0.8221 & 0.8532 & 0.7481 \\
Random Forest & 0.9997 & 0.7750 & 0.9998 & 0.6913 \\
\hline
\end{tabular}




\subsubsection{Deep Learning Experimental Results Comparison}

Similarly, we evaluated two different deep learning algorithms with two classifications. The algorithms were Text-CNN (Johnson and Zhang, 2015) and LSTM (Zhou et al., 2015). They used Word Embedding as the Feature. We found that the Text-CNN was much more accurate than the LSTM.

Table 3. Two different classifications of emails and their numbers of sample emails

\begin{tabular}{l|l|l|l|l}
\hline & \multicolumn{2}{|l|}{ Primary classification (10 categories) } & \multicolumn{2}{l}{ Secondary classification (22 categories) } \\
\hline Algorithm & Training Accuracy & Testing Accuracy & Training Accuracy & Testing Accuracy \\
\hline Text-CNN & 0.9974 & 0.8127 & 0.9824 & 0.7335 \\
LSTM & 0.3260 & 0.2228 & 0.3676 & 0.3287 \\
\hline
\end{tabular}

\subsubsection{Active Learning}

The concept of active learning includes picking out unlabeled samples and improving the classification accuracy of the model by labeling these selected samples (Yang et al., 2009). We divided the unlabeled 412,000 emails into 412 small samples (1000 emails per copy). First, we initialized the model with 5000 emails that had been marked; this produced the original model. Next, we found the top 300 keywords (the key values are reduced in turn) for each class (22 categories). The keyword was used as the labeling specification to automatically label the first 1000 pieces of unmarked email information. If there were 300 keywords in the specification, then the number of occurrences of the keyword was calculated and multiplied by the weight (this weight was the key value, the most critical word weight was 300, and the last word weight was 1). This proposed the possibility that this email information belonged to 22 categories. We then assigned this email information to the class with the highest probability value. Next, we added the first small sample, which was automatically labeled, to the original data (5000 raw data, plus 1000 new data, 6000 total). Then we redistributed $80 \%$ of training data and $20 \%$ of test data and retrained the CNN and SVM models and tested their accuracies ( $\mathrm{Li}$ et al., 2012). These steps were repeated by continuously growing the training data sample size, testing, and recording accuracy.

In the above steps, we continuously tested and corrected the results of 22 categories of 300 keywords. The first step included finding the number of occurrences of all the words in the 22 categories. If there was overlap in the 22 categories, we removed these words from the labeling specification in order to reduce confusion between classes. For example: unit; instructor; department; management; organization; supervision; advice; time; life; received; government, and other words were considered keywords in all 22 categories and therefore removed. This helped us retain other words that are more discriminative.

To compare the impact of the number of samples added during active learning on the CNN and SVM, we compared the accuracy of the CNN and SVM in regard to sample size. Figure 5 shows that the test accuracy increased as the number of samples increased.
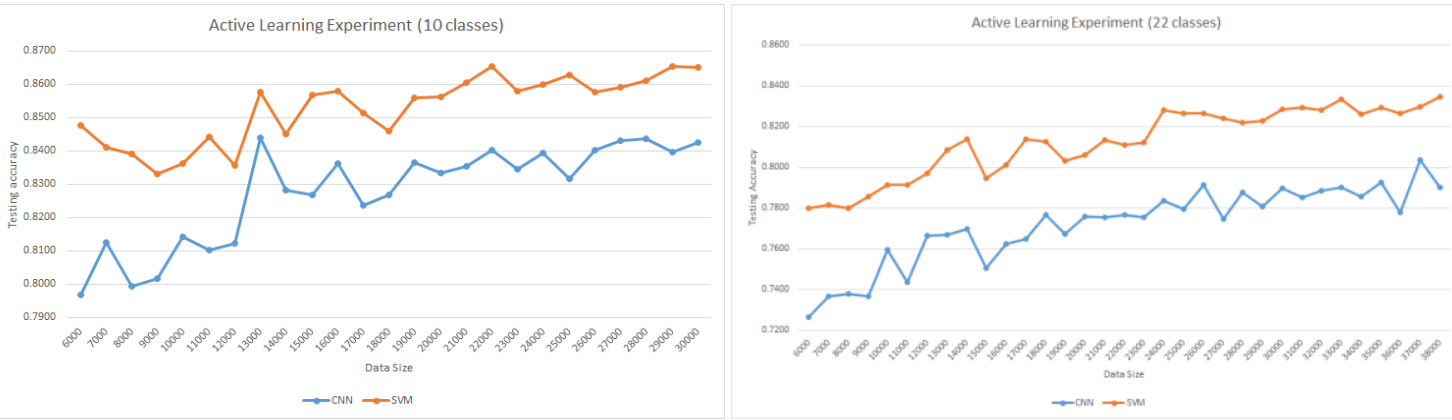

Figure 5. Primary and secondary classification evaluation result comparison of CNN and SVM in active learning

\subsubsection{Spark Parallel Computing}

From October 10, 2013 to June 6, 2020, there was a total of 410,000 emails from citizens collected by the government. After building and optimizing the model through natural language processing, all 410,000 emails can be categorized in 6 hours - which is much faster than can be done manually. By using spark parallel computing (Figure 1), the computing time was further reduced from 6 hours to 21 minutes, which improves the efficiency even more (Liu et al., 2019). 


\section{CONCLUSION}

Urban informatics has become an increasingly important domain in the past few years. This has corresponded to the growth in the diversity and volume of urban data resources. This paper uses machine learning and deep learning methods, along with natural language processing technology, to mine and analyze citizens' emails. This process includes cutting email content which is then digitized by natural language processing technology and modeled by a convolutional neural network through deep learning technology as well as with a machine learning model. Finally, each email in the city government's email box can be automatically classified into a variety of topics. This method greatly improves the efficiency of analyzing city information and would be an advantageous tool in regard to governmental decision making. Future work may look to further improve the efficiency of these processes such as by using natural language processing models with transformers.

\section{REFERENCES}

Coussement, K. and Van den Poel, D., 2008. Improving customer complaint management by automatic email classification using linguistic style features as predictors. Decision Support Systems, 44(4), pp.870-882.

Ferilli, S., Esposito, F. and Grieco, D., 2014. Automatic learning of linguistic resources for stopword removal and stemming from text. Procedia Computer Science, 38, pp.116-123.

Genkin, A., Lewis, D.D. and Madigan, D., 2007. Large-scale Bayesian logistic regression for text categorization. Technometrics, 49(3), pp.291-304.

Halaris, C., Magoutas, B., Papadomichelaki, X. and Mentzas, G., 2007. Classification and synthesis of quality approaches in e - government services. Internet research.

Johnson, R. and Zhang, T., 2015. Semi-supervised convolutional neural networks for text categorization via region embedding. In Advances in neural information processing systems (pp. 919-927).

Li, L., Jin, X., Pan, S.J. and Sun, J.T., 2012, August. Multi-domain active learning for text classification. In Proceedings of the 18th ACM SIGKDD international conference on Knowledge discovery and data mining (pp. 1086-1094).

Lilleberg, J., Zhu, Y. and Zhang, Y., 2015, July. Support vector machines and word2vec for text classification with semantic features. In 2015 IEEE 14th International Conference on Cognitive Informatics \& Cognitive Computing (ICCI* CC) (pp. 136-140). IEEE.

Liu, P., Zhao, H.H., Teng, J.Y., Yang, Y.Y., Liu, Y.F. and Zhu, Z.W., 2019. Parallel naive Bayes algorithm for large-scale Chinese text classification based on spark. Journal of Central South University, 26(1), pp.1-12.

Sun, J., 2012. Jieba chinese word segmentation tool. 2018-01-21)[2018-06-25]. https://github. com/fxsjy/jieba.

Tang, D., Wei, F., Yang, N., Zhou, M., Liu, T. and Qin, B., 2014, June. Learning sentiment-specific word embedding for twitter sentiment classification. In Proceedings of the 52nd Annual Meeting of the Association for Computational Linguistics (Volume 1: Long Papers) (pp. 1555-1565).

Thakuriah, P.V., Tilahun, N.Y. and Zellner, M., 2017. Big data and urban informatics: innovations and challenges to urban planning and knowledge discovery. In Seeing cities through big data (pp. 11-45). Springer, Cham.

Wang, Z.Q., Sun, X., Zhang, D.X. and Li, X., 2006, August. An optimal SVM-based text classification algorithm. In 2006 International Conference on Machine Learning and Cybernetics (pp. 1378-1381). IEEE.

Xu, B., Guo, X., Ye, Y. and Cheng, J., 2012. An Improved Random Forest Classifier for Text Categorization. JCP, 7(12), pp.2913-2920.

Yang, B., Sun, J.T., Wang, T. and Chen, Z., 2009, June. Effective multi-label active learning for text classification. In Proceedings of the 15th ACM SIGKDD international conference on Knowledge discovery and data mining (pp. 917-926).

Zhou, C., Sun, C., Liu, Z. and Lau, F., 2015. A C-LSTM neural network for text classification. arXiv preprint arXiv:1511.08630. 